welfare, urban planning and anthropology. Walter B. Cannon (who coined the term 'fight or flight' and was a crucial figure in developing the concept of homeostasis) used Selye's model to explain and validate the phenomenon of 'Voodoo death', describing it as acute homeostatic shock in response to a severe emotional stressor.

There is much of interest to the psychiatrist, but of particular note is Theodore M. Brown's essay on US psychiatry during the Second World War. Discussing the work of (among others) the American psychiatrist Roy Grinker, Brown traces how an important paradigm shift in mental illness occurred. At the beginning of the war, only those with poor personality structure or innate vulnerability were thought to develop neurotic illness under stress. By the end of the war, this view had radically changed. Severe stress and breakdown became something that could happen to anyone. This complete and sudden paradigm shift powerfully destigmatised mental breakdown while simultaneously expanding the realm and scope of psychiatry.

Rhodri Hayward's paper offers fresh perspective on the Brown and Harris study on risk factors for depression, exploring how measures in that study were designed to take account of stress, meaning and narrative in a way that had never been done before. Junko Kitanaka's essay on how workplace stress has been reframed as depression in modern Japan is also a particularly interesting read.

It is fair to say that not all the essays are relevant or interesting to the psychiatrist and as academic papers some are more readable than others. However, they are uniformly accomplished, painstakingly researched and considered reflections on the historical impact of a hugely influential concept that has had surprisingly little consideration till now.

Lisa Conlan locum consultant psychiatrist, South London and Maudsley NHS Foundation Trust, London, UK. Email: lisa.conlan@slam.nhs.uk

doi: 10.1192/bjp.bp.114.158477

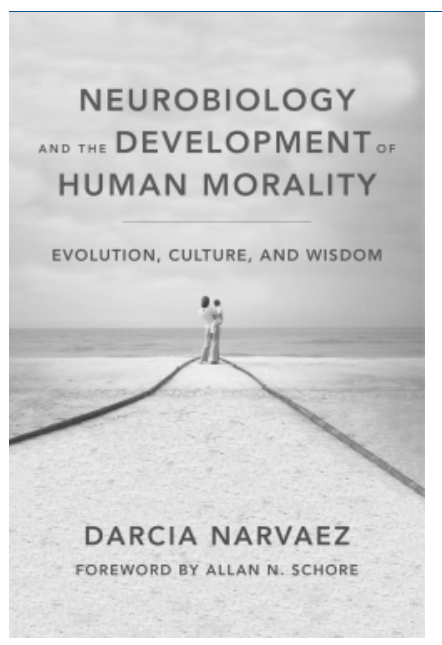

\section{Neurobiology and the Development of Human Morality: Evolution, Culture and Wisdom}

By Darcia Narvaez WW Norton. 2014 US\$ 39.95 (hb). $456 \mathrm{pp}$. ISBN: 9780393706550
This book aims to provide a broad-ranging account of the neuroscience of psychological and moral development. It attempts to place this in the context of the transformation of human societies from our hunter-gatherer origins to modern agricultural and industrial societies and to consider how child-rearing practices have changed as a result of this.

The first part of the book is a review of what is known about how the developing brain can be damaged by negative physical, psychological and social influences. Darvaez does not have a background in neuroscience and seems at times to struggle with her material. Inferences and conclusions fly off the page with what sometimes seems like a lack of caution. For example, she states, 'There is evidence that one's microbiome can also influence personality. Ingested probiotic gut bacteria affect brain signalling . . . enhancing learning, memory and emotional control and at the same time reducing behaviours related to stress, depression and anxiety (Bravo, 2011)' (p.33). It is only by checking the reference that the reader learns that this research was carried out in mice.

Darvaez's ideas on moral development are based on the belief that there is a need to challenge a prevalent view that morality is based on the rational following of rules. In fact, this view was challenged by David Hume, Adam Smith and others in the 18th century and is not widely held by moral philosophers and psychologists. Her belief that morality has to be considered in the context of our evolutionary past is one that has been discussed by many researchers.

A core theme of the book is that there is an 'evolved developmental niche'. This refers to a pattern of child-rearing that Narvaez believes was characteristic of the 'small band hunter gatherer' groups in which humans lived throughout most of our history. This includes parental responsiveness, constant physical presence, breastfeeding ('frequent, infant-initiated, 2-5 years'), multiple adult caregivers, positive social support and free play in nature with multi-aged mates. She states, 'Undercare of our evolved needs in early life leads to deficiencies in [sic] the brain structural integrity, hormonal regulation, and system integration that lead to sociality' (p.126).

She presents a picture of our hunter-gatherer past as a time of prelapsarian innocence in which humans lived in harmony with each other and with the world of nature. She draws on the present-day experiences of Native Americans to support this view but makes no mention of the very serious social problems present in these communities. She believes that the answer to our ills is to return as far as possible to the 'Primal Wisdom' of hunter-gatherer groups and hence to our 'human essence'. This is to be achieved by individuals engaging in a range of ameliorative and therapeutic activities that come under the heading of 'Developmental Ethical Ecological Practice'. With enough effort, therapy and 'self-authorship', it seems that one can undo the damaging effects of a modern-day upbringing on brain and body.

In contrast to the preceding chapters on neuroscience, Darvaez now discards scientific objectivity and replaces it with mysticism. She suggests that we need 'to perceive the beauty and purpose of cosmic divinity, the life force' (p.233) and to seek the support of 'spiritual entities (e.g. angels) or the animals and plants in your neighbourhood...' (p. 263).

There is no discussion of the practical impediments to this project. How is a young mother who, either by choice or economic necessity, returns to the workforce after the birth of her child, to implement a regime of constant physical presence and frequent, on-demand breastfeeding for up to 5 years? There is little mention of the many societal trends such as increasing inequality, urbanisation, stagnant family incomes, overpopulation, marital breakdown and the dispersal of extended families that will militate against this project.

There are reasons to believe that our hunter-gatherer ancestors had lives that were more healthy and fulfilling than the ones that most humans have known since the advent of the Agricultural Revolution. The sad reality is that we are stuck with the consequences of 10000 years of human history and levels of population that cannot be fed by hunting and gathering. 
Narvaez has a writing style that makes for effortful reading. The flow of her prose is continually interrupted by excessive quotation from, and unnecessary reference to, other sources. References are often to books and other secondary sources. The development of her ideas is often difficult to follow.

It should go without saying that it is our duty as parents and citizens to give our children the best possible start in life and to bring them up as responsible and happy members of our communities. The basic requirements of love, concern, physical contact, security and emotional stability are obvious to most people. There is no need to refer to a putative hunter-gatherer past to justify these.
Healthcare systems are already struggling to provide services for the most psychologically disturbed members of our society. We know that focus on especially vulnerable families can produce profound and durable benefits on the life course of children. There can be no justification for the diversion of resources to the kind of untested, population-wide project proposed by Narvaez.

John Callender consultant psychiatrist, Royal Cornhill Hospital, 26 Cornhill Road, Aberdeen AB25 7ZH, UK. Email: jscall@doctors.org.uk

doi: 10.1192/bjp.bp.114.161752 